\title{
Management of primary dysmenorrhea in young women with frameless LNG-IUS
}

This article was published in the following Dove Press journal:

Open Access Journal of Contraception

17 June 2014

Number of times this article has been viewed

\author{
Dirk Wildemeersch ${ }^{1}$ \\ Sohela Jandi² \\ Ansgar Pett ${ }^{2}$ \\ Thomas Hasskamp ${ }^{3}$ \\ 'Gynecological Outpatient Clinic \\ and IUD Training Center, Ghent, \\ Belgium; ${ }^{2}$ Gynecological Outpatient \\ Clinic, Berlin, Germany; ${ }^{3}$ GynMünster, \\ Münster, Germany
}

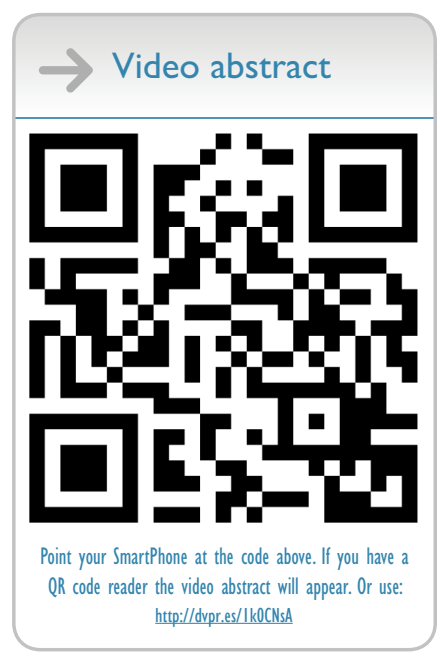

Correspondence: Dirk Wildemeersch Gynecological Outpatient Clinic and IUD Training Center, F Rooseveltlaan 43/44, 9000 Ghent, Belgium

Tel +3250 600900

Fax +32 92342926

Email d.wildemeersch@skynet.be

\begin{abstract}
The objective of this paper is to discuss the potential advantages of intrauterine treatment with a frameless levonorgestrel (LNG)-releasing intrauterine system (IUS) in young women presenting with primary dysmenorrhea associated with heavy menstrual bleeding. The paper is based on clinical reports of 21 cases of primary and secondary dysmenorrhea treated with the frameless LNG-IUS. Three typical examples of young women between 16 and 20 years of age, who presented with moderate-to-severe primary dysmenorrhea associated with heavy menstrual bleeding, are presented as examples. Following pelvic examination, including vaginal sonography, a frameless LNG-IUS, releasing $20 \mu \mathrm{g}$ of LNG/day, was inserted. The three patients developed amenorrhea, or scanty menstrual bleeding, and absence of pain complaints within a few months. We conclude that continuous, intrauterine progestogen delivery could be a treatment of choice of this inconvenient condition. In addition, the good experiences with the frameless LNG-IUS in other studies suggests that the frameless design may be preferred over a framed LNG-IUS, as the absence of a frame, resulting in optimal tolerance, is particularly advantageous in these women.
\end{abstract} Keywords: heavy menstrual bleeding, contraception, FibroPlant, intrauterine system

\section{Introduction}

In an epidemiologic study of an adolescent population, Klein and Litt reported a prevalence of dysmenorrhea of $59.7 \%{ }^{1}$ Of patients reporting pain, $12 \%$ described it as severe, $37 \%$ as moderate, and $49 \%$ as mild. Dysmenorrhea caused $14 \%$ of patients to miss school frequently. ${ }^{1}$

In primary dysmenorrhea, the pain begins with the onset of menstruation or shortly before and persists throughout the first 1-2 days. Women usually report constant lower abdominal pain with superimposed uterine cramps, which radiate to the back or anterior and/or medial thigh. Associated general symptoms, such as malaise and fatigue (85\%), nausea and vomiting (89\%), diarrhea $(60 \%)$, lower backache $(60 \%)$, and headache (45\%), may be present with primary dysmenorrhea. Dizziness, nervousness, and can also be associated with primary dysmenorrhea. ${ }^{2}$

Primary or spasmodic dysmenorrhea occurs typically in late adolescence and the early 20s. Primary dysmenorrhea should be distinguished from secondary dysmenorrhea. In primary dysmenorrhea, the underlying basis is myometrial hyperactivity which causes local hypoxia due to an increased local secretion of vasopressin and prostaglandins. ${ }^{3}$ The causes of secondary dysmenorrhea are diverse: intrauterine pathology (eg, fibroids, adenomyosis, intrauterine device [IUD] incompatibility), extrauterine pathology (eg, endometriosis), and outflow obstructions (eg, cervical stenosis). Secondary dysmenorrhea is most often observed in women aged 30-45 years. ${ }^{4}$ 
Many conservative treatment options have been tried to alleviate menstrual pain in women with primary dysmenorrhea, such as nonsteroidal anti-inflammatory drugs (NSAIDs) and combined oral contraceptives (OCs) and, in secondary dysmenorrhea, hysterectomy and endometrial ablation. ${ }^{4} \mathrm{Few}$ studies have been conducted in women with primary and secondary dysmenorrhea with the Mirena ${ }^{\circledR}$ levonorgestrel (LNG)releasing intrauterine system (IUS) (Bayer AG, Leverkusen, Germany). These studies were mainly conducted in women with chronic pelvic pain associated with endometriosis. ${ }^{5-7}$ As many women with primary dysmenorrhea are very young, a LNG-IUS that is small and flexible could be preferred in women with this unfortunate condition. ${ }^{8}$ The current report is an evaluation of the potential of the frameless LNG-IUS in young women with primary dysmenorrhea associated with heavy menstrual bleeding. This paper will discuss the potential advantages of the frameless LNG-IUS over the framed LNGIUSs and other treatment schedules.

\section{Materials and methods \\ Patients}

The patients in this case presentation were identified among a group of young, nulliparous women participating in a prospective contraceptive study with the frameless LNG-IUS. They were selected in a sequential manner if they presented with painful and heavy menstrual periods.

The history included age at menarche; menstrual frequency; length of period; estimate of the menstrual flow; associated symptoms (eg, nausea, vomiting, or other symptoms); severity of pain and its relationship to the menstrual cycle (women who had to stay at home were considered to have severe dysmenorrhea); impact on physical and social activity; and progression of symptom severity. All women were nulliparous and complied with the World Health Organization eligibility criteria for IUD insertion. ${ }^{9}$

\section{Description of the frameless FibroPlant $^{\circledR}$ LNG-IUS (Contrel Research, Ghent, Belgium)}

The frameless design was selected for use in these patients as this design eliminates any pain complaints as a result of dimensional factors, which are frequent causes of cramping pain with conventional IUDs, particularly in nulliparous women.

The frameless LNG-IUS is a new concept. It is a multicomponent system consisting of a nonresorbable suture thread (polypropylene), at the proximal end of the suture thread is a single knot. Attached thereto is a 3.0 or $3.5 \mathrm{~cm}$-long and 1.2 or $1.6 \mathrm{~mm}$-wide fibrous delivery system, releasing approximately
$14 \mu \mathrm{g}$ and $20 \mu \mathrm{g}$ of LNG per day, respectively. The low-dosage release system is effective for 3 years and the higher dosage LNG-IUS for 5 years. The fiber is fixed to the anchoring thread by means of a metal clip $1 \mathrm{~cm}$ from the anchoring knot. The anchoring knot is implanted into the myometrium of the uterine fundus using an insertion instrument, permanently securing the device in the uterine cavity (Figure 1A). The metal clip is visible on ultrasonography and X-ray, allowing proper location of the IUS in the uterine cavity at insertion and on follow-up (Figure 1B). The technique of insertion is identical to that of the frameless GyneFix ${ }^{\circledR}$ copper IUD (Contrel Research) (see video insertion at http://www.wildemeersch. com/user/nl/insertie-video).

In the present study, the effect of treatment on pain complaints during menstruation was assessed by verbal questioning during follow-up examination. Menstrual pain during treatment was graded as follows: no pain; almost no pain; much reduced pain; no change in pain compared with before. The amount of blood loss was evaluated in 18 of the 21 patients using a simple visual assessment technique to discriminate between menorrhagia and normal menstrual blood loss. ${ }^{10}$ Following insertion, an ultrasound scan was performed to verify the proper location of the LNG-IUS in the uterus. Follow-up was conducted at 1, 3, and 12 months, and yearly thereafter. The first 18 women received the 3 -year product and the remaining women the 5-year LNG-IUS. All insertions were done by the same author in a private practice setting.

\section{Results}

An overview of the patient characteristics and results in the total number of women $(n=21)$ treated with the frameless LNG-IUS for primary and secondary dysmenorrhea is given in Table 1. Nine women in the study were nulliparous. Six women were 20 years of age or less.
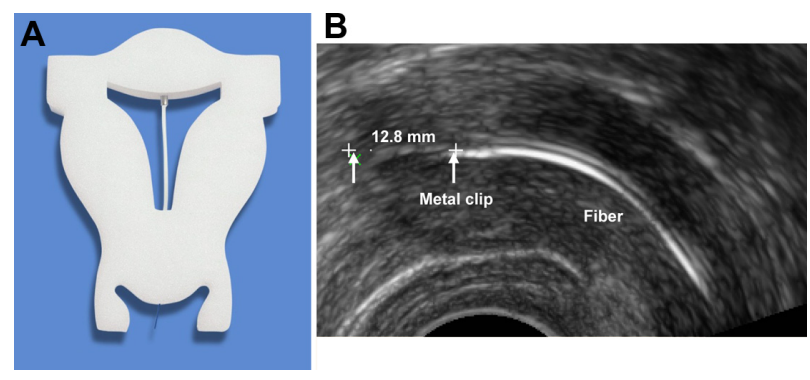

Figure I FibroPlant ${ }^{\circledR}$ levonorgestrel-releasing intrauterine system.

Notes: (A) FibroPlant ${ }^{\circledR}$ levonorgestrel-releasing intrauterine system (Contrel Research, Ghent, Belgium) attached to the fundus in a foam uterus. (B) Twodimensional sonography showing the levonorgestrel-releasing fiber which follows the curvature of the uterus. The metal clip is located $12.8 \mathrm{~mm}$ from the serosa. 
Table I Characteristics of the study group and events in 21 FibroPlant ${ }^{\circledR}$ levonorgestrel-releasing intrauterine system (Contrel Research, Ghent, Belgium) users for the treatment of primary and secondary dysmenorrhea

\begin{tabular}{|c|c|c|c|c|}
\hline User & Indication & $\mathbf{G} / \mathbf{P}$ & $\begin{array}{l}\text { Age at insertion } \\
\text { (years) }\end{array}$ & $\begin{array}{l}\text { Evaluation (number of months after } \\
\text { insertion) }\end{array}$ \\
\hline \multicolumn{5}{|c|}{ Primary dysmenorrhea } \\
\hline $\mathrm{I}$. & Primary dysmenorrhea, heavy bleeding & $0 / 0$ & 43 & $\begin{array}{l}29 \text { months: almost complete absence of pain, scanty } \\
\text { menstrual bleeding }\end{array}$ \\
\hline 2. & Primary dysmenorrhea, heavy bleeding & $\mathrm{I} / \mathrm{I}$ & 44 & 25 months: no pain, scanty menstrual bleeding \\
\hline 3. & Primary dysmenorrhea, oligomenorrhea & $0 / 0$ & 18 & 20 months: no pain, almost total absence of bleeding \\
\hline 4. & Primary dysmenorrhea, heavy menstrual bleeding & $2 / 2$ & 47 & I8 months: no pain, scanty menstrual bleeding \\
\hline 5. & Primary dysmenorrhea, normal menstruations & $0 / 0$ & 16 & 16 months: no pain, scanty menstrual bleeding \\
\hline 6. & Primary dysmenorrhea, heavy bleeding & $0 / 0$ & 39 & $\begin{array}{l}12 \text { months: much reduced pain, scanty menstrual } \\
\text { bleeding }\end{array}$ \\
\hline 7. & Primary dysmenorrhea, normal menstruations & $\mathrm{I} / \mathrm{I}$ & 30 & I3 months: no pain, much reduced bleeding \\
\hline 8. & Primary dysmenorrhea, normal menstruations & $0 / 0$ & 16 & 3 months: much reduced pain and bleeding \\
\hline 9. & Primary dysmenorrhea, heavy menstrual bleeding & $0 / 0$ & 16 & 3 months: no pain and no menstrual bleeding \\
\hline 10. & Primary dysmenorrhea, heavy menstrual bleeding & $0 / 0$ & 17 & 3 months: no pain and no menstrual bleeding \\
\hline II. & Primary dysmenorrhea, heavy menstrual bleeding & $0 / 0$ & 20 & 3 months: no pain, scanty menstrual bleeding \\
\hline 12. & Primary dysmenorrhea, normal menstruations & $\mathrm{I} / \mathrm{I}$ & 49 & II months: no pain, much reduced bleeding \\
\hline \multicolumn{5}{|c|}{ Secondary dysmenorrhea } \\
\hline 13. & $\begin{array}{l}\text { Secondary dysmenorrhea, heavy bleeding, } \\
\text { suspicion of adenomyosis }\end{array}$ & $2 / 2$ & 42 & 28 months: much reduced pain and bleeding \\
\hline 14. & $\begin{array}{l}\text { Secondary dysmenorrhea, heavy bleeding, } \\
\text { presence of significant fibroids }\end{array}$ & $\mathrm{I} / \mathrm{I}$ & 43 & 26 months: much reduced pain and bleeding \\
\hline 15. & $\begin{array}{l}\text { Secondary dysmenorrhea, heavy bleeding, } \\
\text { presence of small fibroids }\end{array}$ & $\mathrm{I} / \mathrm{I}$ & 45 & 22 months: no pain, much reduced bleeding \\
\hline 16. & Secondary dysmenorrhea, heavy bleeding & $\mathrm{I} / \mathrm{I}$ & 59 & 28 months: no pain, amenorrhea \\
\hline 17. & $\begin{array}{l}\text { Secondary dysmenorrhea, heavy bleeding, } \\
\text { suspicion of adenomyosis }\end{array}$ & $\mathrm{I} / \mathrm{I}$ & 47 & I5 months: no pain, scanty menstrual bleeding \\
\hline 18. & $\begin{array}{l}\text { Secondary dysmenorrhea, heavy bleeding, } \\
\text { presence of significant fibroids }\end{array}$ & $3 / 3$ & 35 & II months: no pain, scanty menstrual bleeding \\
\hline 19. & $\begin{array}{l}\text { Secondary dysmenorrhea, heavy bleeding, } \\
\text { presence of small fibroids }\end{array}$ & $0 / 0$ & 49 & $\begin{array}{l}12 \text { months: no pain, much reduced menstrual } \\
\text { bleeding }\end{array}$ \\
\hline 20. & $\begin{array}{l}\text { Secondary dysmenorrhea, presence of significant } \\
\text { fibroids }\end{array}$ & $1 / 1$ & 50 & 9 months: no pain, much reduced bleeding \\
\hline 21. & $\begin{array}{l}\text { Secondary dysmenorrhea, heavy bleeding, } \\
\text { suspicion of adenomyosis }\end{array}$ & $2 / 2$ & 45 & 5 months: much reduced pain and bleeding \\
\hline
\end{tabular}

Note: G/P: Gravida (number of pregnancies)/Para (number of deliveries).

\section{Case presentations \\ Case I}

The first patient was 16 years of age when she consulted with her mother for severe dysmenorrhea, heavy periods, and desire for contraception. Menarche had started at the age of 13 years. During consultation with a doctor, she complained of menstrual pain which started from her first menstruation for which anti-inflammatory drugs provided some relief. The pain began 1 day before menstruation and lasted for 2 days. Although the pain complaints were severe, she was reluctant to leave school and endured the pain. She did not report associated symptoms. Menses were reported as heavy, particularly during the first days. No abnormalities were found during gynecological examination, which included sonography. Following premedication ( $400 \mu \mathrm{g}$ of misoprostol orally, 3 hours before insertion) and local, intracervical anesthesia $(1.8 \mathrm{~mL}$ of $3 \%$ mepivacaine with dental syringe), a frameless LNG-IUS (FibroPlant ${ }^{\mathbb{R}}$ ) was easily inserted and fixed to the fundus of the uterus. The insertion was done immediately after cessation of menstruation. On follow-up, 3 months after insertion, the patient reported no complaints. Menstruations stopped completely after 1 month. On examination, the frameless IUS was properly located in the uterine cavity. Eighteen months later, menses were scanty with no or very slight pain.

\section{Case 2}

This 17-year-old patient presented with moderate-to-severe dysmenorrhea for approximately 2 years. She also complained of heavy menstrual bleeding that had begun with menarche at the age of $12-13$ years. The menstrual pain started 1 day before menstruation and lasted for 3-5 days. She described the pain as continuous discomfort in the lower abdomen 
superimposed by painful cramps. The pain had not become worse over the last 2 years, but impacted her physical and social activity. On pelvic and sonographic examination, no gynecological abnormalities could be identified. Information was provided about the treatment possibilities. As the patient also required contraception, she opted for a frameless LNGIUS, which was inserted at the end of menstruation following premedication with misoprostol, $400 \mu \mathrm{g}, 3$ hours orally prior to insertion. At follow-up, 3 months after insertion, the patient reported no bleeding and no pain complaints.

\section{Case 3}

The third patient was 20 years old, with menarche having begun at 14 years of age, and complained of severe distress during menstruation. The painful periods had started a few years earlier and had a severe impact on her social life. She could not leave home for at least 2-3 days during menstruation. The pain started on the first day of menstruation, which was the worst day, and lasted for the whole period. Over the last 2 years, the painful periods had become progressively worse, with headaches, sweats, and hot flushes. Menses were usually heavy. No genital abnormalities could be found on pelvic examination, which included sonography of the pelvic organs. She opted for the frameless LNG-IUS, which provides contraception, reduction of menstrual bleeding, and relief of pain. At 3 months follow-up, the patient reported no pain complaints, no headaches, and scanty menstruation requiring only small pads.

\section{Comments and discussion}

In this study, conducted in 21 patients with primary and secondary dysmenorrhea, the frameless LNG-IUS was the only method used to alleviate the menstrual pain complaints. Twelve women were categorized as having primary dysmenorrhea, as no organic cause for the painful menstrual periods could be found. In 12 women, an anomaly of the uterus was found. Three women had significant multiple intramural or subserosal fibroids, as confirmed by sonography and magnetic resonance imaging. Two other women had small fibroids and four had enlarged uteri without other apparent uterine anomalies. Three women were suspected to have uterine adenomyosis. All women in this study reported much reduced pain, or no pain at all, and strongly reduced bleeding, which started as soon as 1 month after insertion of the frameless LNG-IUS. There was one exception in a woman with significant fibroids. She reported much reduced bleeding, but this was not as pronounced as in the other women in the study. Thirteen women had at least 12 months follow-up and four had more than 2 years.
The women in the case reports presented with typical primary dysmenorrhea. The pain was associated with heavy menstrual bleeding and the reported pain complaints were severe. The young women often had to stay in bed, and the pain prevented them from attending school. Their pain complaints were absent at follow-up after 3 months and they had no or scanty menstrual bleeding.

In the clinical management of dysmenorrhea, NSAIDs, which inhibit prostaglandin synthesis, offer a valid treatment. This medication is the most commonly used treatment for this condition. ${ }^{11}$ Because the pain results from uterine vasoconstriction, anoxia, and contractions mediated by prostaglandins, symptomatic relief can often be obtained from use of agents that inhibit prostaglandin synthesis and have anti-inflammatory and analgesic properties. They are generally well tolerated and free of serious toxicity. Gastrointestinal upset is the most common adverse effect associated with NSAIDs, and patients receiving these medications should be monitored for more serious adverse effects, including gastrointestinal bleeding and renal dysfunction. The disadvantage is that NSAIDs do not have a strong enough impact on the endometrium to be able to treat associated heavy menstrual bleeding, and they are not contraceptive.

Combined OCs are used often to treat dysmenorrhea, especially in young women who also require contraception. OCs reduce uterine contractility, suppress the endometrium, and reduce endometrial prostaglandin concentrations. However, the effect is limited and the side effects and potential for adverse drug reactions may limit their use in some women. Use of OCs in a manner that reduces the number of menstrual cycles (by extending the use of active pills and avoiding the pill-free week or with extended-cycle formulations) may be beneficial for some patients. ${ }^{12}$

Continuous intrauterine LNG delivery causes uniform suppression of the endometrium throughout the whole thickness of the mucosa, which is maintained by the high tissue concentrations, and reduces the prostaglandin synthesis in the endometrium. ${ }^{13}$ The LNG-IUS also provides contraception and simultaneously reduces heavy menstrual bleeding, often resulting in amenorrhea. Continuous, intrauterine progestogen delivery could, therefore, be the treatment of choice for sexually active women and women with associated heavy menstrual bleeding.

\section{Frameless versus framed LNG-IUS for the treatment of dysmenorrhea}

As uterine cavities differ considerably in size and shape, and the uterus is subject to changes in size and volume during 
the menstrual cycle, it would be unreasonable to expect one standard-sized IUS to fit in uterine cavities that differ in size and volume from woman to woman and from time to time in the same woman. Clinical experience has shown that disproportion between the IUS and the uterine cavity can lead to partial or total expulsion, perforation of the uterine wall, pain, unintended pregnancy, and abnormal or heavy uterine bleeding leading to early removal of the device. ${ }^{8}$ Research has also shown that, if the width of the uterine cavity is too small, side effects and complications are likely to occur. ${ }^{14}$ The length of the transverse arm of the Mirena LNG-IUS is $32 \mathrm{~mm}$. The average fundal transverse dimension in nulliparous as well as parous women, determined using measuring instruments (Cavimeter ${ }^{\mathbb{B}}$, Wing-sound) inserted in the uterus, is only $25 \mathrm{~mm} .{ }^{15}$

Recent three-dimensional (3-D) sonography studies confirm the narrow transverse diameter of the uterine fundus in many women. Benacerraf et al measured the fundal transverse diameter in over 200 nulliparous women (group 1), in women with one child (group 2), and in women with more than one child (group 3) and found that the fundal transverse diameter varied from 20.2 to $34.1 \mathrm{~mm}$ in the first group, from 22.9 to $36.3 \mathrm{~mm}$ in group 2, and from 24.6 to $37.5 \mathrm{~mm}$ in group $3 .{ }^{16}$

Other 3-D studies compared women with abnormally located and women with normally located IUDs with respect to their indication for sonography examination and found that the proportion of patients whose principal indication for the examination was bleeding, pain, or bleeding and pain was significantly greater in those with an abnormally located IUD, including embedded IUDs, compared with those whose IUD was not found on 3-D sonography to be located abnormally. ${ }^{17}$ The authors commented that standard two-dimensional sonography is not able to detect many abnormally located IUDs, particularly with regard to abnormal location of the side arms of the IUD. Accurate location of the side arms is only possible with 3-D coronal sonography or by hysteroscopy, as shown in Figure 2.

A study in current and former copper-T IUD users found a dissatisfaction rate of $34 \% .{ }^{18}$ The reason for the discontinuation in this study was not available, but previous studies showed that heavy bleeding and pelvic pain were the most commonly cited reasons for discontinuing copper-T IUDs. It is therefore logical, as has been confirmed in clinical trials, that harmony between the size of the foreign body and the dimensions of the uterine cavity is essential as regards its acceptability, the occurrence of side effects, and the continued use of the method. ${ }^{19}$ The frameless copper-releasing GyneFix IUDs and the frameless FibroPlant LNG-IUS were developed to optimize harmony with the uterine cavity of parous and nulliparous women in an
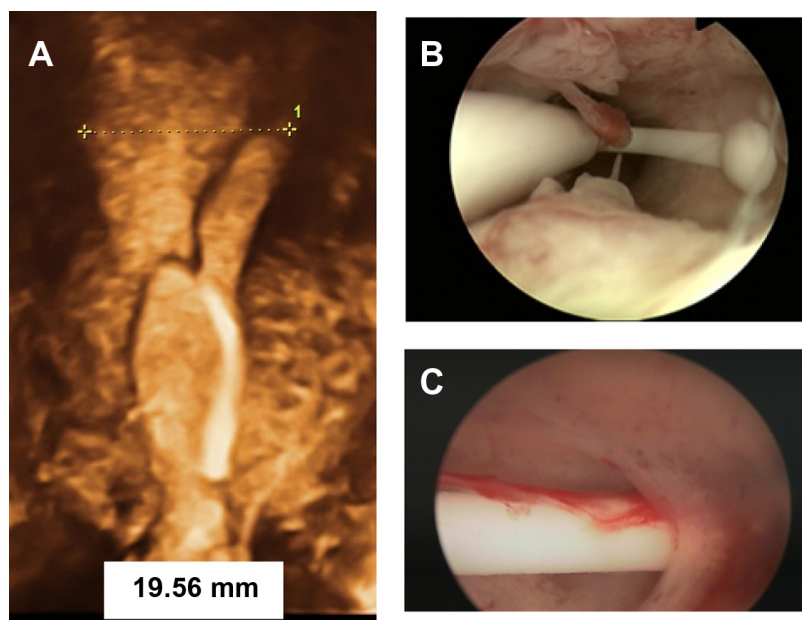

Figure 2 Examples of incompatibility between the intrauterine device and the uterine cavity.

Notes: Severe disproportion caused by the side arms of the Mirena ${ }^{\circledR}$ levonorgestrelreleasing intrauterine system (Bayer AG, Leverkusen, Germany) being too long. The transverse diameter at the fundus is only $19.56 \mathrm{~mm}(\mathbf{A})$. Unfolded transverse arm $\left(\right.$ Merena $\left.{ }^{\circledR}\right)$ (B). Transverse arm of a Mirena intrauterine device penetrating the uterine wall causing abnormal bleeding $(\mathbf{C})$.

attempt to reduce the side effects and expulsion rates of conventional IUDs and, consequently, increase continuation of use. Figure 3 illustrates the position of the frameless and flexible FibroPlant LNG-IUS in a uterus of which the fundal transverse diameter is smaller than the average uterine width.

In addition to the advantageous design features of the frameless LNG-IUS, of significant importance are both the high contraceptive effectivity and high effectiveness in managing menstrual bleeding, as observed in clinical trials. ${ }^{20}$ The "obligatory" anchoring of the frameless LNG-IUS in the uterine fundus reduces the risk of expulsion. Expulsion rates up to $8 \%$ at 1 year of use have been observed in adolescent

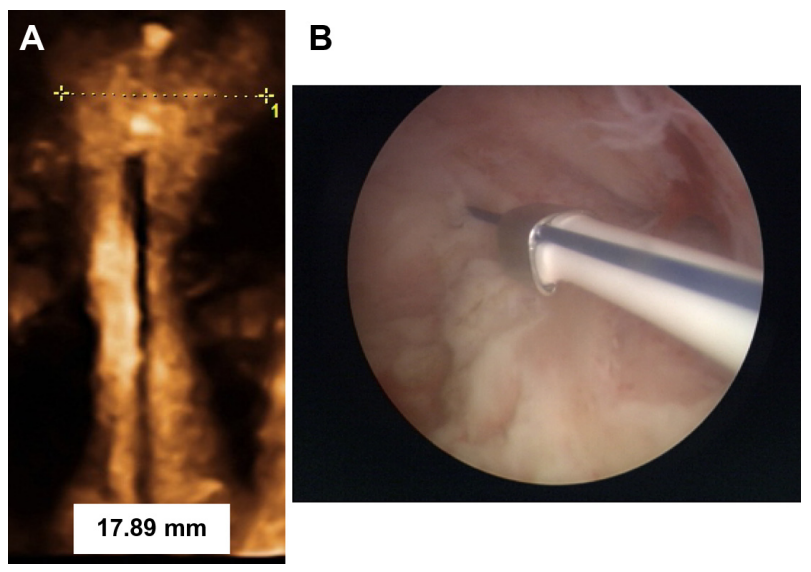

Figure 3 FibroPlant ${ }^{\circledR}$ levonorgestrel-releasing intrauterine system in situ. Notes: Three-dimensional sonography of the frameless FibroPlant ${ }^{\circledR}$ levonorgestrelreleasing intrauterine system (Contrel Research, Ghent, Belgium) (A) and a hysteroscopy picture of the frameless intrauterine system anchored to the fundus of the uterus (B). 
women using framed LNG-IUS, as well as high removal rates for pain complaints during the first year. ${ }^{21,22}$

The limitations of this study are its small number of women and the absence of comparative data. One could question, however, if it would be recommendable to young women presenting with severe dysmenorrhea to insert a LNG-IUS considering the possibility that it would likely not fit in the uterine cavity, unless the cavity width was measured, and shown to be large enough to adapt to a large-size LNG-IUS.

\section{Conclusion}

A LNG-IUS could successfully be used for the treatment of primary dysmenorrhea in young women. Reported experiences with the frameless LNG-IUS of young nulliparous and adolescent women with primary dysmenorrhea suggest that the frameless design may be preferred over a framed LNGIUS, as the absence of a frame is particularly advantageous in these women. As only a small number of women were evaluated in this study, additional, larger scale studies should be conducted, preferably including a comparator, to confirm the results obtained in this study.

\section{Disclosure}

D Wildemeersch has been involved in the optimization of new, innovative drug delivery systems for use in the uterus. He is currently an advisor involved in devising new concepts in controlled release for contraception, gynecological treatment, and prevention of infectious diseases. The authors report no other conflicts of interest in this work.

\section{References}

1. Klein JR, Litt IF. Epidemiology of adolescent dysmenorrhea. Pediatrics. 1981;68:661-664.

2. Dawood MY. Dysmenorrhea. J Reprod Med. 1985;30:154-167.

3. Äkerlund M. The pathophysiology of dysmenorrhea. In: Cameron IT, Fraser IS, Smith SK, editors. Clinical Disorders of the Endometrium and Menstrual Cycle. Oxford: Oxford University Press; 1998:281-288.

4. Lumsden MA. The clinical treatment of dysmenorrhea. In: Cameron IT, Fraser IS, Smith SK, editors. Clinical Disorders of the Endometrium and Menstrual Cycle. Oxford: Oxford University Press; 1998:289-296.

5. Bahamondes L, Petta CA, Fernandes A, Monteiro I. Use of levonorgestrel-releasing intrauterine system in women with endometriosis, chronic pelvic pain and dysmenorrhea. Contraception. 2007;75: S134-S139.

Open Access Journal of Contraception

\section{Publish your work in this journal}

Open Access Journal of Contraception is an international, peerreviewed, open access, online journal, publishing original research, reports, reviews and commentaries on all areas of contraception. In addition to clinical research, demographics and health-related aspects, the journal welcomes new findings in animal and preclinical studies
6. Vercellini P, Aimi G, Panazza S, De Giorgi O, Pesole A, Crosignani PG. A levonorgestrel-releasing intrauterine system for the treatment of dysmenorrhea associated with endometriosis: a pilot study. Fertil Steril. 1999;72:505-508.

7. Bayer LL, Hillard PJ. Use of levonorgestrel intrauterine system for medical indications in adolescents. $J$ Adolesc Health. 2013;52: S54-S58

8. Wildemeersch D, Pett A, Jandi S, Hasskamp T, Rowe P, Vrijens M. Precision intrauterine contraception may significantly increase continuation of use: a review of long-term clinical experience with frameless copper-releasing intrauterine contraception devices. Int $J$ Womens Health. 2013;5:215-225.

9. World Health Organization (WHO). Medical eligibility criteria for contraceptive use. Geneva, Switzerland: WHO, 3rd edition 2004.

10. Janssen CA, Scholten PC, Heintz AP. A simple visual assessment technique to discriminate between menorrhagia and normal menstrual blood loss. Obstet Gynecol. 1995;85:977-982.

11. Daniels SE, Torri S, Desjardins PJ. Valdecoxib for treatment of primary dysmenorrhea. A randomized, double-blind comparison with placebo and naproxen. J Gen Intern Med. 2005;20:62-67.

12. Sillem M, Schneidereit R, Heithecker R, Mueck AO. Use of an oral contraceptive containing drospirenone in an extended regimen. Eur $J$ Contracept Reprod Health Care. 2003;8:162-169.

13. Nilsson CG, Luukkainen T, Arko H. Endometrial morphology of women using a d-norgestrel-releasing intrauterine device. Fertil Steril. 1978;29:397-401.

14. Shipp TD, Bromley B, Benacerraf BR. The width of the uterine cavity is narrower in patients with an embedded intrauterine device (IUD) compared to a normally positioned IUD. $J$ Ultrasound Med. 2010;29:1453-1456.

15. Kurz KH. Cavimeter uterine measurements and IUD clinical correlation. In: Zatuchni GI, Goldsmith A, Sciarra JJ, editors. Intrauterine Contraception: Advances and Future Prospects. Philadelphia, PA: Harper and Row; 1984:142-162.

16. Benacerraf BR, Shipp TD, Lyons JG, Bromley B. Width of the normal uterine cavity in premenopausal women and effect of parity. Obstet Gynecol. 2010;116:305-310.

17. Benacerraf BR, Shipp TD, Bromley B. Three-dimensional ultrasound detection of abnormally located intrauterine contraceptive devices which are the source of pelvic pain and abnormal bleeding. Ultrasound Obstet Gynecol. 2009;34:110-115.

18. Moreau C, Cleland K, Trussell J. Contraceptive discontinuation attributed to method dissatisfaction in the United States. Contraception. 2007;76:267-272.

19. Wildemeersch D. Commentary. Intrauterine contraceptives that do not fit well contribute to early discontinuation. Eur J Contracept Reprod Health Care. 2011;16:1-7.

20. Andrade A, Wildemeersch D. Menstrual blood loss in women using the frameless FibroPlant LNG-IUS. Contraception. 2009;79: 134-138.

21. Paterson H, Ashton J, Harrison-Woolrych M. A nationwide study of the use of the levonorgestrel intrauterine device in New Zealand adolescents. Contraception. 2009;79:433-438.

22. Suhonen S, Haukkamaa M, Jakobsson T, Rauramo I. Clinical performance of a levonorgestrel-releasing intrauterine system and oral contraceptives in young nulliparous women: a comparative study. Contraception. 2004;69:407-412.

\footnotetext{
Submit your manuscript here: http://www.dovepress.com/open-access-journal-of-contraception-journal
}

relating to understanding the biological mechanisms and practical development of new contraceptive agents. The manuscript management system is completely online and includes a very quick and fair peer-review system. Visit http://www.dovepress.com/testimonials.php to read real quotes from published authors. 